\title{
NOVEJŠI TOKOVI URBANIZACIJE V SLOVENIJI
}

\author{
Marjan Ravbar*
}

IZVLEČEK

UDK 911.375.227 (497.12)

Članek prikazuje najnovejše spremembe $\mathrm{v}$ demografskem razvoju mest in drugih naselij ter prostorskih enot v SR Sloveniji.

ABSTRACT

UDC 911.375 .227 (497.12)

THE LATEST TENDENCES OF URBANISATION IN SLOVENIA

The present paper enlights the latest changes in demographic development of citics and other settlements in territory units in the Socialist Republic of Slovenia.

Urbanizacija se kot zgodovinski in svetovni proces z razvojem drižbeno-ekonomskih in clovekovih aktivnosti spreminja. Dinamika urbanizacije je po svetu razlixna. Odvisna je od razlik $v$ razvitosti posameznih dežel ter odnosov $v$ načinu življenja med mestom in podeželjem. Od tod izhajajo tudi intenzivne migracije prebivalstva. J.P. Gibbs (1963) je pri urbanizaciji razlikoval procese koncentracije in dekoncentracije prebivalstva. Pojav je $v$ industrijskih deželah razdelil v pet razvojnih stopenj: od faze moxne koncentracije prebivalstva $v$ mestih in depopulacije prebivalstva na podeželju do razseljevanja prebivalstva iz mest in nastajanje novega poselitvenega vzorca na "dežcli" (countryurbanisation). Za manj razvite dežele velja, da se urbanizacija odraža v cksplozivni rasti mestnega prebival- stva, ki je nckajkrat veæja of rasti skupnega števila prebivalstva. $\mathrm{V}$ razvitih deželah pa so oblike nadaljnega urbanega razwoja drugaěne. Porast mestnega prebivalstva se giblje $\mathrm{v}$ glavnem $\mathrm{v}$ okvirih dinamikc rasti skupnega Stevila prebivalcev. Selitveni tokovi prebivaistva iz ruralnih obmoxij v mesta postopno slabijo, krepi pa se preseljevanje $\mathrm{v}$ obmestna obmoxja. Težišce urbanizacije, prebivalstvo, delovna mesta in stanovanjska naselja se presiavIjajo iz mest v primestne cone in podeželska obmoxja. Tako se evropska obmest ja od druge polovice కestdesetih let nahajajo $v$ fazi impresivne metamorfaze. Industrializacija in suburbanizacija spreminjajo njihovo morfologijo in morfologijo in socialno-ckonomsko strukturo.

In $v$ kakšni fazi urbanizacijskih procesov se nahaja Slovenija? S priðujocim prispevkom želimo osvetliti novejక̌e spremembe, ki nastopajo v demografsken razvoju mest in ostalih naselij po obxinah SR Slovenije. Analiza temelji na prouxitvi demografskih sprememb in deloma selitvenih procesov med slovenskimi mesti in ostalimi naselji.

* Mag., Inštitut za geografijo Univerze Edvarda Kardelja, 61000 Ljubljana, Trg Irancoske revolucije 7 , YU. 
Čeprav je za Slovenijo znaxilna razmeroma nizka stopnja urbanizacije, so tudi tu v tem $v$ povojnem obdobju nastale precejšnje spremembe. Pod vplivom industrializacije smo bili $\mathbf{v}$ sestdesetih in sedemdesetih letih prixa celo forsirane urbanizacije (Vrǐer, 1969), ko se je delež mestnega prebivalstva postopoma dvigoval od $36,1 \%$ v letu 1961 na 44,6 \% v letu 1971 in 48,9\% v letu 1981 . V tem kratkem obdobju se je urbanizacija napajala pretežno $s$ poudarjenimi migracijami prebivalstva s podeželja in dinamið̌nim razvojem malih mest. Povpreð̌ne letne stopnje rasti mestnega prebivalstva so se v tem obdobju $1961 / 71$ znasale $2,15 \%$ in v obdobju $1971 / 812,05 \%$, medtem ko je skupno prebivalstvo narašalo po letni stopnji $0,6 \%$ v prvem in $1,1 \%$ v drugem obdobju. Koeficient koncentracije prebivaistva, izrađunan med razmerjem indeksa rasti mestnega prebivalstva proti rasti prebivalstva $\mathrm{v}$ ostalih naseljih je za obdobje 1961/ 81 znasal 1,53.

Po letu 1981 (deloma že v drugi polovici sedemdesetih let) opa- žamo umirjanje rasti mestnega prebivalstva. Do leta 1986 se je delež mestnega prebivalstva sicer povzpel na $50,1 \%$, vendar se je povpreðna letna stopnja rasti znižala na $1,4 \%$, ob tem da skupno prebivalstvo v republiki narašca po $1,0 \%$ letni stopnji. Koefi- cient koncentracije prebivalstva se je v obdobju 1981/86 povzpel na $1,05 \mathrm{kar}$ pomeni, da miestna naselja కe narašcajo za $5 \%$ hitreje od ostalih naselij. Tako se proces koncentracije prebivalstva $\mathrm{v}$ mestih zmanjšje $\mathrm{v}$ korist urbanizacije sirక̌e pokrajine, kar pomeni prehod iz sekundarne v terciarno - postindustrijsko fazo urbanizacije.

Tabcla 1: Srednje letne rasti mestnega prebivalstva v obdobjih 1981/71 in 1986/81 glede na delež mestnega prebivalstva v SRS

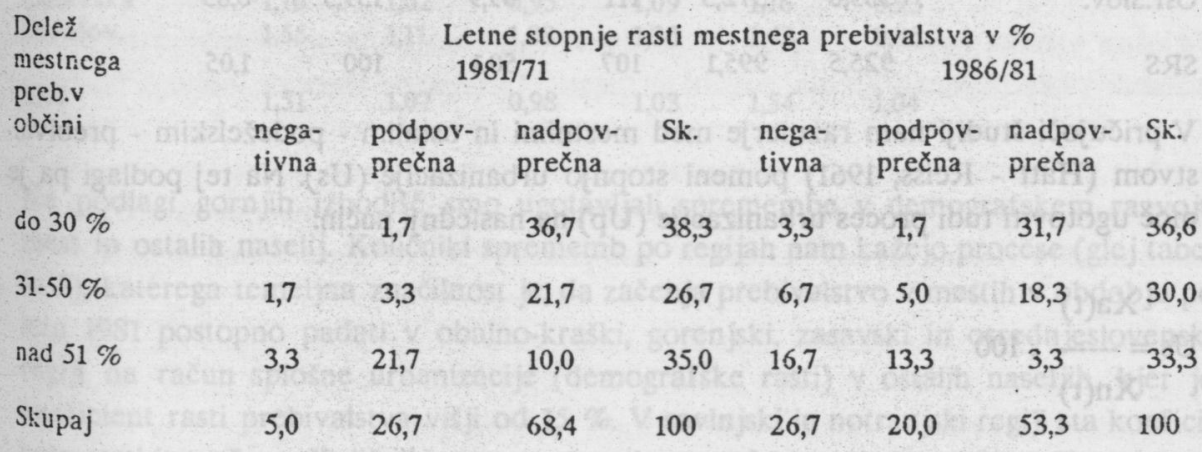

Kljub temu, da je delež mestnega v letu 1986 presegel polovico vsega prebivalstva v republiki, obstajajo కe vedno velike razlike med obæinami (glej tabelo 1 in 2). Medtem ko je prebivalstvo $\mathrm{v}$ obdobju 1981/71 $\mathrm{v}$ večini slovenskih mest క̌e narašalo, (v dveh tretjinah mest celo po nadpovprecni stopnji) po letu 1981 v več kot cetrtini mestno prebivalstvo že upada $\mathrm{v}$ vec kot cetrtini obঝin. Upadanje mestnega prebival- 
stva je izrazitejకe v obmoð jih $\mathrm{z}$ nadpovpređnim deležem urbanega prebivalstva. Tabela 2. gornjo trditev le se potrjuje. $\mathrm{V}$ mestnih regijah (obxinah $\mathrm{z}$ nadpovprexnim deležem mestnega prebivalstva), Osrednjeslovenska, Gorenjska, Zasavska in Obalno-kraకka, opažamo uravnoteženo rast urbanega in neurbanega prebivalstva. Koeficienti koncentracije nas opozarjajo na splošno urbanizacijo pokrajine kot posledico disperzne rasti nemestnih naselij. V imenovanih regijah mestna naselja že absolutno zaostajajo za rastjo nemestnih naselij. Za podpovprečno razvite regije: predvsem Pomurje, pa tudi Dolenjsko, Spodnje Posavje, Gorisko in Notranjsko కe vedno veljajo procesi koncentracije prebivalstva v mestih, vendar so po letu 1981 manj intenzivni.

Tabela 2: Gibanje mestnega prebivalstva po regijah SRS 1981-86

\begin{tabular}{|c|c|c|c|c|c|c|}
\hline \multirow[b]{2}{*}{ Regija } & \multicolumn{2}{|c|}{ st.preb.v mestih } & \multirow{2}{*}{$\begin{array}{l}\text { Indeks } \\
86 / 81\end{array}$} & \multicolumn{2}{|c|}{ Delež urb.preb.1986 } & \multirow{2}{*}{$\begin{array}{l}\text { koef. } \\
\text { konc. } \\
1986 / 81\end{array}$} \\
\hline & $\begin{array}{r}1981 \\
\mathrm{v}\end{array}$ & 1986 & & v \% & & \\
\hline Pomurska & 25,1 & 27,2 & 108 & 20,6 & 41,1 & 1,08 \\
\hline Podravska & 158,3 & 164,0 & 104 & 49,9 & 99,6 & 1,02 \\
\hline Koroška & 29,5 & 31,7 & 107 & 43,2 & 86,2 & 1,04 \\
\hline Savinjska & 88,0 & 95,1 & 108 & 37,2 & 74,3 & 1,01 \\
\hline Sp.Posavje & 22,0 & 23,4 & 106 & 32,2 & 64,3 & 1,08 \\
\hline Dolenjska & 30,3 & 32,9 & 109 & 32,3 & 64,5 & 1,06 \\
\hline Goriška & 35,6 & 38,0 & 107 & 36,9 & 73,6 & 1,07 \\
\hline Obalno-kraš. & 51,7 & 54,8 & 106 & 55,4 & 110,6 & 0,93 \\
\hline Notranjska & 18,0 & 18,7 & 104 & 37,0 & 73,8 & 1,01 \\
\hline Gorenjska & 100,5 & 105,5 & 105 & 55,8 & 111,4 & 0,99 \\
\hline Zasavslia & 30,9 & 31,5 & 102 & 66,1 & 131,9 & 0,93 \\
\hline Osr.Slov. & 335,6 & 372,3 & 111 & 69,9 & 139,5 & 0,83 \\
\hline SRS & 925,5 & 995,1 & 107 & 50,1 & 100 & 1,05 \\
\hline
\end{tabular}

V pričjoči studiji nam razmerje med mestnimi in ostalim - podežcls'ím - prebivalstvom (Hatt - Reiss, 1961) pomeni stopnjo urbanizacije (Us). Na tej podlagi pa je mox ugotoviti tudi proces urbanizacije (Up) na naslednji nacin:

$$
\begin{aligned}
& \mathrm{Us}=\frac{\mathrm{Xa}(\mathrm{t})}{\mathrm{Xn}(\mathrm{t})} \cdot 100 \\
& \begin{array}{l}
U s(t) \\
U s(t-1)
\end{array}=\frac{X a(t) \cdot X n(t-1)}{X n(t) \cdot X a(t-1)}
\end{aligned}
$$

$\mathrm{Xa}=$ kazalec dosežcne stopnje razvoja v mestih (npr. St.preb., št.priseljenih, ipd.)

$\mathrm{Xn}=$ kazalec dosežcne stopnje razvoja $\mathrm{v}$ ostalih naseljih $\mathrm{v}$ doloceni teritorialni enoti $\mathrm{t}, \mathrm{t}-1=$ casovna obdobja 
Tako zasnovana formula nam za vsako teritorialno enoto (ob $x_{i n o)}$ prikazuje stopnjo urbanizacije. Proces urbanizacije (Up) pa potemtakem spremembe, ki jih lahko ugotavljamo za razlixne kazalce. Vrednosti nad 1,0 pomenijo relativno rast, vrednosti pod 1,0 pa relativen padec. Pri tem je pomembno se to, da absoluten padec kazalca v imenovalcu pomeni prav tako vrednosti nad 1,0 .

Tabela 3: Gibanje prebivalstva v mcstnih in ostalih naselij SR Slovenije 1961/81 in 1981/86 po regijah

koeficienti sprcmemb stevila prebivalstva

Regija mestna nas. ostala nas.

$61 / 81 \quad 81 / 86 \quad 61 / 81 \quad 81 / 86 \quad a / c \quad b / d$
(a)
(b)
(c)
(d)
(e)
(f)

$\begin{array}{lllllll}\text { Pomurska } & 1,73 & 1,08 & 0,93 & 0,99 & 1,86 & 1,09 \\ \text { Podravska } & 1,33 & 1,03 & 0,98 & 1,02 & 1,36 & 1,01 \\ \text { Koroska } & 1,53 & 1,07 & 0,93 & 1,03 & 1,65 & 1,04 \\ \text { Savinjska } & 1,73 & 1,08 & 1,02 & 1,08 & 1,70 & 1,00 \\ \text { Sp.Posavje } & 1,46 & 1,06 & 0,91 & 0,98 & 1,60 & 1,08 \\ \text { Dolcnjska } & 1,80 & 1,08 & 0,97 & 1,02 & 1,85 & 1,06 \\ \text { Goriłka } & 1,86 & 1,07 & 0,90 & 0,99 & 2,07 & 1,08 \\ \text { Obalno-kraska } & 1,74 & 1,06 & 0,94 & 1,14 & 1,85 & 0,93 \\ \text { Notranjska } & 1,43 & 1,03 & 0,87 & 1,02 & 1,64 & 1,01 \\ \text { Gorenjska } & 1,44 & 1,05 & 1,13 & 1,06 & 1,27 & 0,99 \\ \text { Zasavska } & 1,10 & 1,02 & 0,95 & 1,09 & 1,16 & 0,93 \\ \text { Osr.slov. } & 1,55 & 1,11 & 1,08 & 1,30 & 1,43 & 0,85 \\ \text { SRS } & & & & & & \\ & 1,51 & 1,07 & 0,98 & 1,03 & 1,54 & 1,04\end{array}$

Na podlagi gornjih izhodišc smo ugotavljali spremembe $\mathrm{v}$ demografskem razvoju mest in ostalih naselij. Koliixniki sprememb po regijah nam kažcjo procese (glej tabelo 3), katerega temeljna znacilnost jc, da zacenja prebivalstvo $\mathrm{v}$ mestih $\mathrm{v}$ obdobju po letu 1981 postopno padati v obalno-kraß̌ki, gorenjski, zasavski in osrednjeslovenski regiji na račun splošne urbanizacije (demografske rasti) $v$ ostalih nascljih, kjer je koeficient rasti prebivalstva visji od $15 \%$. V savinjski in notranjski regiji sta koeficicnta rasti izenaðena. Količniki sprememb v demografski rasti mest, ki so bili v obdobju 1961/81 v povpreðju క̌c za $50 \%$ višji od nemestnih naselij so se po leltu 1981 tudi v ostalih slovenskih regijah umirili.

Po posameznih teritorialnih enotah opažamo večje spremembe (glej karto 1). Obstoja korelacija med spremembami rasti prebivalstva $\mathrm{v}$ mestnih in nemestnih naseljih med opazovanima obdobjema. N jena vrednost je 0,5514 , kar prixa o diferenciranem 
razvoju urbanizacije v Sloveniji. Na podlagi kolixnikov kvantitativnih - demografskih kazalcev smo pripravili tipologijo občin glede na spremembe $v$ demografskem razvoju mest in ostalih naselij po letu 1981. Slovenske obđine mox̌ razvrstiti v devet skupin razlixnih kombinacij relativnega zaostajanja, stagnacije ali rasti mestnih in ostalih naselij. Opazne spremembe $\mathrm{v}$ urbanizacijskih procesih smo razvrstili $\mathrm{v}$ stiri glavne skupine:

Najobsežnejšo skupino predstavljajo obCine za katere je bila v obdobju 1961/81 znacilna mo¿na koncentracija prebivalstva (indeks rasti okoli 200) v mestih, ob rahlem nazadovanju $\mathrm{v}$ ostalih naseljih. Po letu 1981 prebivalstvo $\mathrm{v}$ mestih narašca pocasneje tudi na rađ̌un rasti prebivalstva v ostalih naseljih (Nova Gorica, Velenje, Metlika, Scžana, Gornja Radgona). V nekoliko bolj omiljeni obliki se podobni procesi pojavljajo క̌ v obðinah Novo mesto, Krško, Slovenska Bistrica, Radlje, Radovljica,itd. Drugo skupino predstavljajo obðine, kjer prebivalstvo $\mathrm{v}$ mestnih naseljih narašca tudi po letu 1981 ob tem, da prebivalstvo v ostalih naseljih ne upada vec: Murska Sobota, Žalec, Grosuplje, Ptuj, Cerknica, Lenart in Trebnje. Za tretjo skupino velja, da se vsesplošna intenzivna rast mestnega prebivalstva (indeks rasti $150-200 \%$ ) in v ostalih naseljih (nad $120 \%$ ) nadaljuje tudi po letu 1981 v približno enakih razmerjih. Takßne so predvsem obそ̌ne v కirక̌sm obmestju Ljubljane: Kranj, Domžale, Kamnik ter ljubljanske obð̌ine Við Rudnik, Mcste - Polje in Šiška. Zadnjo skupino obđ̌in pa predstavlja 16 ob丈in, ki do leta 1981 కe beležijo hitrejšo demografsko rast v mestih. Po tem letu pa opažamo absoluten ali relativen zaostanek v demografskem razvoju v primerjavi z ostalimi naselji. Takక̌nc znaxilnosti imajo Jesenice, Škof ja Loka, Idrija, Vrhnika, Ravne, zasavskc in obalne obcine, Cclje, Koðevje in mariborske obcine.

Splošna oznaka prikazane tipologije je, da naselja z relativno najmođncjకo rast prcbivalstva obkrožajo stiri naకa najvěja mesta: Ljubljano, Maribor, obalna mesta in Celjc. Radij vpiivov je v prcmen sorazmer ju $z$ njihovo velikostjo. Izjema so stara mozno industrializirana in urbanizirana, toda degradirana obmozja: Jesenice, Tržiz, Mežica, Revirji, kjer prebivalstvo $v$ mestih prav tako upada ob istočasni rasti primestnih naselij, vendar zaradi "ekoloskih" komponent - beg iz degradiranih obmoxij. 
Tabela 4: Razvoj mestnih (M) in nemestnih (NM) naselij po velikostnih kategorijah mest v obdobju 1971/86.

Število preb. v 000

\begin{tabular}{|c|c|c|c|c|c|}
\hline \multirow[t]{2}{*}{$\begin{array}{l}\text { Velikost } \\
\text { mest }\end{array}$} & 1981 & 1986 & $1981 / 71$ & \multicolumn{2}{|c|}{$1986 / 81$} \\
\hline & M NM & M NM & M NM & $\mathbf{M}$ & NM \\
\hline 5.000 & $49,7218,6$ & $53,4219,3$ & $2,53-0,27$ & 1,45 & 0,06 \\
\hline 0 & $112,5 \quad 262,5$ & $\begin{array}{lll}120,0 & 269,2\end{array}$ & $2,12 \quad 0,05$ & 1,30 & 0,50 \\
\hline $10-20.000$ & $159,3204,7$ & $170,4208,2$ & $1,85-0,09$ & 1,35 & 0,34 \\
\hline $20-100.000$ & $212,1181,5$ & $226,4189,8$ & $2,52 \quad 0,39$ & 1,31 & 0,89 \\
\hline nad 100.000 & $391,7 \quad 99,2$ & $425,2 \quad 103,9$ & $1,79-0,23$ & 1,66 & 0,93 \\
\hline up & 925,3 & $995,4990,4$ & $2,04-0,05$ & 1,47 & 0,4 \\
\hline
\end{tabular}

Tabela 4, ki prikazuje razvoj mestnega in nemestnega prebivalstva po velikostnih skupinah mest, nas opozarja na naslednje zakonitosti: nadpovprexna rast malih mest (do 10.000 prebivalcev) se je po letu 1981 umirila in poslej razvojni procesi v mestih niso odvisni od njihove velikosti. Medtem, ko je bil v prvem obdobju ritem koncentracije merjen $\mathrm{z}$ rastjo mest in upadanjem کtevila prebivalcev $\mathrm{v}$ nemestnih naseljih కe v obratnem sorazmerju $z$ velikostjo mest, opažamo po letu 1981 najmox̌nejšo rast prebivalstva ob najvex jih mestih.

Kljub temu, da se vedno diržijo trditve, da je prebivalstvo Slovenije sorazmerno selitveno imobilno, opažamo tudi v migracijskih gibanjih spremembe. Če je bil v sestdesetih pozitivni migracijski saldo omejen v pretežni meri na mestna naselja in so bili znacilni selitveni tokovi s podeželja v mesta ali bližino zaposlitvenih središc (Klemencič, 1971), opažamo v osemdesetih letih postopne spremembe $v$ migracijskih tokovih. Selitveni tokovi postopno potckajo $\mathrm{v}$ obratno smer iz mestnih središx na mestno obrobje. Prav selitve, so po mnenju Stevilnih avtorjev osnovno gibalo suburbanizacije (Tabela 5).

Delež priseljenega prebivalstva $\mathrm{v}$ slovenskih mestih $\mathrm{v}$ vsem opazovanem obdobju rahlo upada od 52,3\% v letu 1971 na $51,4 \%$ v letu 1986 . Zato pa je delež priseijenih v ostalih naseljih po letu 1981 porastel (indeks 105). Število priseljenih v nemestnih naseljih, ki so v porastu prebiva!stva v obdobju 1981/71 predstavljali komaj šestino, se je povzpelo na ve` kot polovico. Migracijski saldo je po letu $1981 \mathrm{v}$ dveh tretjinah mest (37) negativen in le v šestini mestnih naselij (10) občin. Korelacija med deležem migracij $\mathrm{v}$ številu prebivalstva in povprexno letno stopnjo rasti prebivalstva je pri nemestnih naseljih 0.7772 , pri mestnih pa le 0.4202 . 
Tabela 5: Spremembe $v$ selitveni mobilnosti prebivalstva med mestnimi in ostalimi naselji v Sloveniji med leti 1971 in 1986

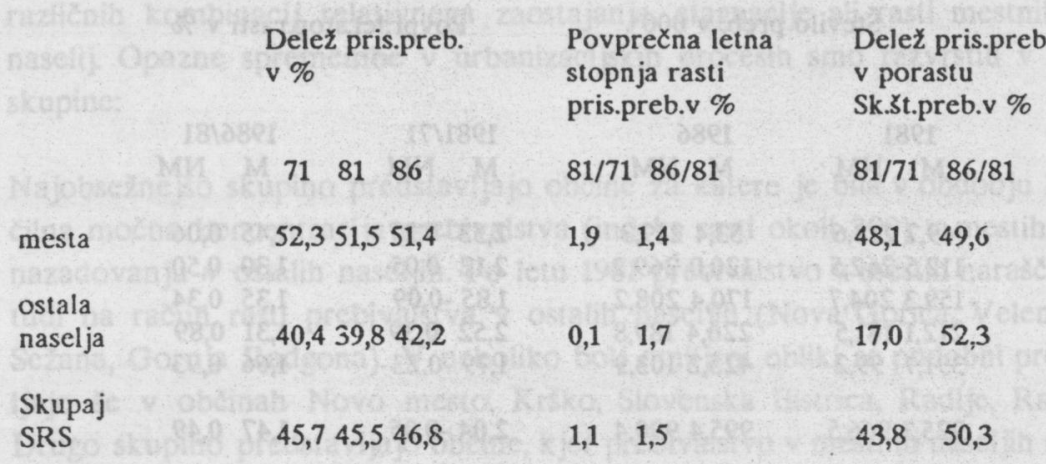

Narašanje prebivalstva na podeželju je povezano tudi $z$ disperznim razvojem zaposlovanja (predvsem zavestnega odpiranja industrijskih delovnih mest) v vsem povojnem obdobju. Tako je bilo koncem 1988. leta 805.167 vseh delovnih mest razporejenih $\vee 2.206$ naseljih ali $\vee$ vsakem tretjem naselju $\vee$ Sloveniji $(36,7 \%)$. Prevladujejo naselja $z$ do 30 delovnimi mesti, kjer je $v 1.462$ nascljih $13,6 \%$ vseh zaposlenih $v$ Sloveniji. Naselij z ve飞 kot 100 delovnimi mesti je 326 . Vendar je v njih $67 \%$ vseh delovnih mest. $\mathrm{V}$ naseljih $\mathrm{z}$ vec kot 50 delovnimi mesti je leta 1986 prebivalo 1.243 mio prebivalcev ali $62,4 \%$ prebivalstva Slovenije. Poleg intenzivne dnevne migracije v zaposlitvena rediša, opažamo tudi intenzivno rast prebivalstva v teh naseljih. Če demografska gibanja $v$ teh naseljih primer jamo $\mathrm{z}$ mestnini, opazimo podobne suburbanizacijske tendence, le da so కe izrazitejక̌e: medtem, ko so mesta do leta 1981 na splošno కe opazno hitreje demografsko narašala (indeks rasti mest 1981/71 je bil 122,5 , v naseljih $\mathrm{z}$ več kot 50 delovnih mest pa 115,2) od podeželskih središ̌ z znatnejsim številom delovnih mest. Čeprav ob starih industrijskih mestih (Jesenice, Trbovlje, Idrija, Zagorje) in obmestnih naseljih Ljubljane in Maribora že tedaj opažamo zaostajanje mest. Po letu 1981 pa je opazen obrat, ko hitrejæăa rast naselij z veð̌ kot 50 delovnimi mesti postaja splošen proccs v vec kot polovici slovenskih obðin. Korelacija sprememb med demografskimi procesi mest in naselij $\mathrm{z}$ vecjim številom delovnih mest $\mathrm{z}$ vrednostjo 0,899 kaže na visoko stopnjo enotnosti decentralizacijskih procesov $v$ vseh slovenskih občinah. Kolixnik sprememb indeksov rasti mest in nemestnih naselij v obdobju 1986/81 znasa 0,99 , kar pomeni, da mesta na splosno relativno zaostajajo za dinamiko rasti podeželskih naselij z delovnimi mesti. (Indeks rasti mest 1986/ 81 je 107,5, nemestnih naselij z vexjim Stevilom delovnih mest pa 108,5).

Disperzija delovnih mest je zato tudi eden od razlogov za zaostajanje vloge slovenskega urbanega omrežja. Možnost zaposlovanja v obsegu dnevne migracije od kraja bivanja prav tako pogojuje, da slovensko prebivalstvo zametuje preseljevanje $v$ 
mesta in raje biva na podeželju. Tako se $\mathrm{v}$ zadnjih desetih letih ne srecujemo $\mathrm{z}$ urbanizacijo, ampak s suburbanizacijo. To je s pojavom rasti obmestnih naselij in nasclij z znatnejšim Stevilom delovnih mest ter zastojem v razvoju mest. Proces sicer ni napacen, a nadalje slabi mesta in pospešje že tako pretirano razpř̌enost poselitve $v$ Sloveniji. V dolocenem smislu je tradicionalno razprßena poselitev $\mathrm{v}$ osemdesetih letih dobila nove vzgibe.

Sodex po dosedanjih raziskavah novejsih tokov urbanizacije poteka med mesti in ostalimi naselji dolocena diferenciacija, ki je rezultat dviga standarda in potrošnje, motorizacije in nadaljnje deagrarizacije ter spremenjene vloge nckaterih terciarnih dejavnosti (Vrišer, 1988). Upada tudi vloga mest. Namesto njih se je pomnožilo క̌tevilo najmanjకih središc, ki združujejo industrijski obrat, krajevno skupnost, trgovino za osnovno preskrbo, osnovno šlo in morda kakšno obrt. Takšna nasclja se funkcijsko krepijo, prebivalstvo v njih pa narašca. Teh naselij je bio v obdobju 1971/81 v Sloveniji 2.338 , v obdobju $1981 / 86$ pa 2.921 . V nasel jih s pozitivno demografsko rastjo je leta 1981 prebivalo 73,2 \%, leta 1986 pa 74,3\% prebivalstva Slovenije. Razvoj odnosov med mesti in podeželjem že v veliki meri poteka v smeri zmanjక̌evanja razlik. Pri tem obe strani sprejemata od nasprotne dolocene scstavine in kvalitete, kar vodi $\mathrm{k}$ pojavu "ruralno-urbanega kontinuuma", to je prostorske stvarnosti, kjer so razlike med mesti in podeželjem majhne, brez pomembnejsih cczur in $\mathrm{z}$ malo razlikami $\mathrm{v}$ materialni opremi. $\mathrm{V}$ zaledjih večine slovenskih mest nastajajo nove pođieželske naselbinc, ki imajo urbani znaxaj in fiziognomijo podežc!skega naseija. Predysem so prednosti mest najbolj omajane zaradi ekoloških razner. Moderne komunikacije in izboljక̌an promet ter ostala infrastruktura omogocajo bo!j razloženo posclitcv. Ti procesi so sicer scle v zacetni fazi, vendar kažejo tendence nove "teritorialne delitve cela", kar krči agrarna in krepi ostala podežciska naselja (predvscñ primestna) z ugodnimi bivalnimi pogoji, zgrajeno infrastrukturo ter dobrimi prometnimi zvezami. 


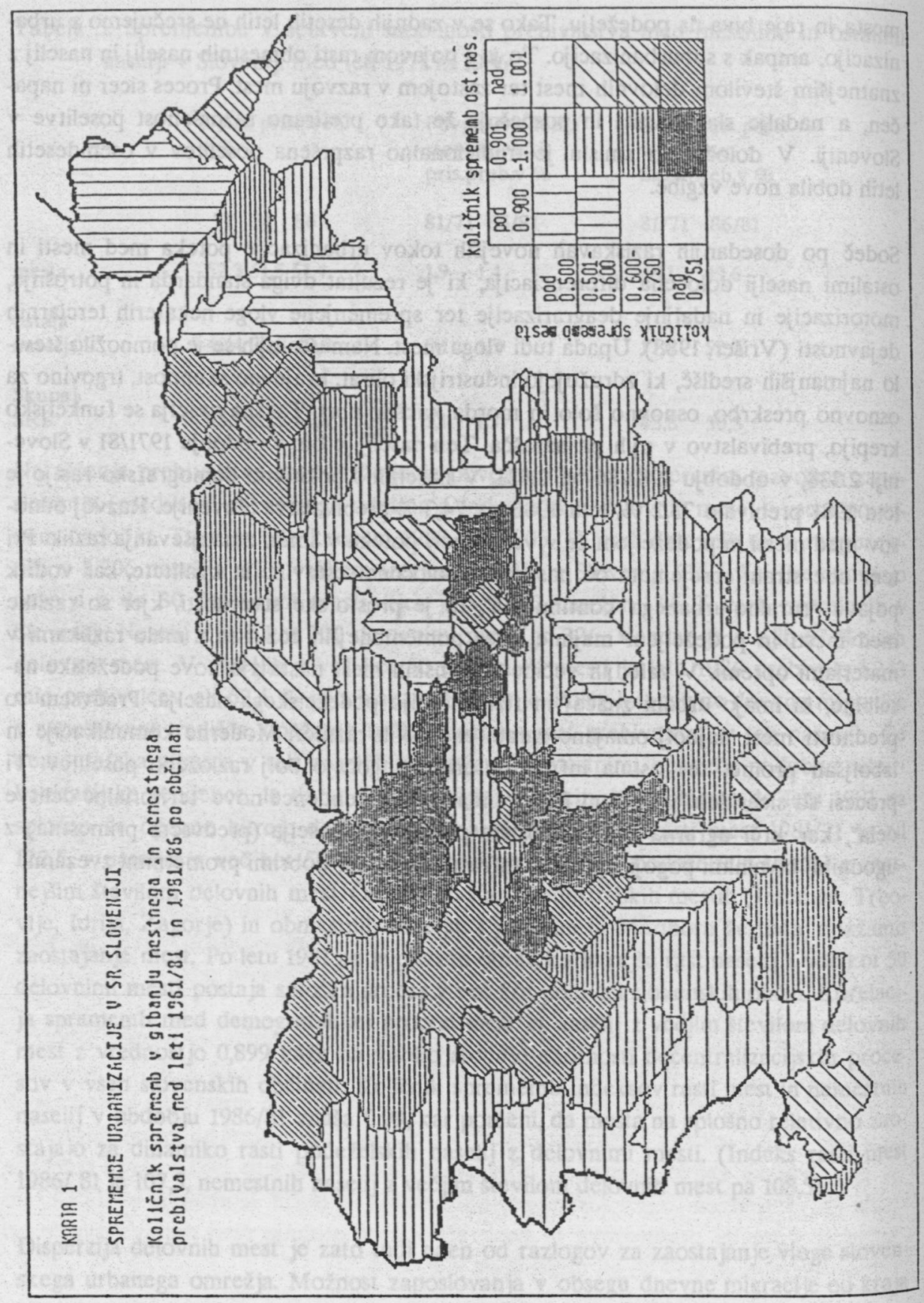




\section{LITERATURA}

Gibbs, J.P., 1963: The Evolution of Population Concentration, Economic Geography, Vol 39, No 2, str. 119-129.

Hatt, P.K. - Reiss A.J., 1961: Cities and Socicty. New York, 2.izpop. izdaja, str. 79.

United Nations 1976: The Determinants and Concequences of Population Trends. Vol. I, New York.

Vriß̌r, I., 1969: Mala mesta v SR Sloveniji. Institut za geografijo Univerze v Ljubljani, Ljubljana, str. 37.

Kokole, Vl., 1962: Funkcije slovenskih mest. Geografski vestnik XXXIV, Ljubljana, str. 21-60.

Vrǐ̌er, I., 1968: Centralna naselja v Jugoslaviji. Ekonomska revija 4, Ljubljana.

Vrišcr, I., 1988: Policentrizem v Sloveniji. IB - revija za planiranje XXIII, st. 5, Ljubljana, str. 11-17.

Vrišer, I., 1988: Centralna naselja v SR Sloveniji leta 1987. Geografski zbornik XXVIII, L jubl jana, str. 129-147.

Klemencix, V., 1971: Prostorska diferenciacija Slovenije po selitveni mobilnosti prebivalstva. Geografski zbornik XII, Ljubljana, str. 197. 


\section{THE LATEST TENDENCIES OF URBANISATION IN SLOVENIA}

The present paper enlights the latest changes in demographic development of cities and other settlements in territory units in the Socialist Republic of Slovenia. We drew attention to the deferences among detached areas in Slovenia which are shown in the dynamics of urban processes. The analysis of assigned processes, which are qualified by numerous authors as suburbanisation, was based cxclusively on analysis of demographic changes and the migration proces between cities and other settlements.

Aftcr 1981 (partly already in the second half of seventies) a calm growth of city inhabitants can be observed. Up to 1986 the share of city inhabitants rose to $50,1 \%$, but the average annual growth fell down to $1,4 \%$, taking in to account the fact that the total growth in the republic is $1,0 \%$ per year. The quotient of inhabitants concentration grew during the period $1986-86$ up to $1,05 \%$ what means that the cities grow only $5 \%$ faster than other settlements. So the process of inhabitant concentration dininishes in the favour of wider landscape urbanisation. The degree of urbanisation (Us) and the process of urbanisation (Up) were statcd as follows:

$\mathrm{Xa}(\mathrm{t})$

Us $=\cdots(t) \cdot 100$

$\mathrm{Xn}(\mathrm{t})$

$U p=\frac{U s(t)}{U s(t-1)}=\frac{X a(t) \cdot X n(t-1)}{X n(t) \cdot X a(t-1)}$, where is

$\mathrm{Xa}=$ indicator of the reached development degree in the cities

$\mathrm{Xn}=$ indicator of the reached development degree in other settlements in a certain territory unit

$t,(t-1)=$ period of time

This formula shows for Us the urbanisation degrec in percentage share towards the whole area in the treated territory unit. Up shows the changes which can be cstablished for various indicators. The values above 1.0 mean relative growth and the values under 1.0 just the opposite - the relative fall. Here is also important the absolute fali of the indicator in the denominator which aiso means the values above 1.0. 
On this bases the typology of communities, considering the changes in demographic development of the cities and other settlements during the period 1981-86 was prepared. Quotient valuation of city inhabitants motion portion and of degree of changes showed that the Slovene communities can be classified (by both criterion) in to seven groups of various combination of relative laggardness, stagnation or growth of the cities, namely other settlements. General mark of the shown typology is that the spreading process of relatively the strongest growth of non-city settlements inhabitants is moving from the areas with the most intensive urbanisation processors to those areas which were considered (upon general asserted criterion) as less urbanised.

The research showed thatthe development of relations between cities and provinces claps in a great part in a direction of diminishing differences. Either side take from the other certain elements and qualities, what leads to "rural-urban continuancy" phenomenon, i.e. spatial reality where are differences between cities and province very small, without more important censorship and without differences in material equipment. Development tendencies are shown in most of the Slovene cities hinterland, where new province settlements with urban character and province settlement physiognomy grow. The advantages of the cities are most weakened due to ecological conditions. Modern communications and improved traffic as well as other infrastructure enable more spreaded settlement. The observed processes are in the early stage but the tendencies of new "territorial division of labour" are shown. They reduce the agrarian settiements and strengthen other provincial settlements (especially those near the cities) with satisfactory living conditions, built infrastructure and good traffic connections. 